\title{
MESOFAUNA TANAH: DIVERSITAS DAN KELIMPAHANNYA PADA BEBERAPA TIPE PENGGUNAAN LAHAN BERBEDA DI BOGOR, JAWA BARAT
}

\author{
Soil Mesofauna: Diversity and Their Abundance on Different Land Use Type in Bogor \\ Region, West Java
}

\author{
Rendy Anggriawan*1, Ronny Mulyawan², Putri Tria Santari ${ }^{3}$ \\ ${ }^{1}$ Program Studi Agroteknologi, Fakultas Pertanian Universitas Muhammadiyah Jember \\ ${ }^{2}$ Program Studi Agroteknologi, Fakultas Pertanian Universitas Lambung Mangkurat \\ ${ }^{3}$ BPTP Balitbangtan Kalimantan Barat \\ e-mail: *rendyagr@gmail.com
}

\begin{abstract}
ABSTRAK
Keberadaan mesofauna tanah bergantung pada sumber energi seperti bahan organik dan biomassa hidup yang terkait dengan aliran siklus karbon di dalam tanah. Penelitian ini bertujuan untuk mengidentifikasi kelimpahan dan keragaman mesofauna tanah pada tiga tipe penggunaan lahan di Bogor, Jawa Barat. Pengambilan sampel tanah dilakukan pada 5 titik lokasi sampel pada tipe penggunaan lahan hutan, kebun, dan tegalan. Ekstraksi mesofauna tanah pada masingmasing tipe penggunaan lahan menggunakan metode berlese tulgren, kempson extractor, dan pitfall traps. Kelimpahan mesofauna tanah terbesar terdapat pada tipe penggunaan lahan tegalan yang diekstraksi menggunakan metode kempson sampel seresah dengan densitas 835 individu $/ \mathrm{m}^{2}$. Indeks diversitas tertinggi meso fauna tanah terdapat pada tipe penggunaan lahan hutan.

Kata kunci: barlesse tulgren, collembolan, kempson extractor, pitfall traps
\end{abstract}

\section{ABSTRACT}

The existence of soil mesofauna has depended on energy sources such as organic matter and living biomass associated with carbon cycle flow in the soil. This study aims to identify the abundance and diversity of soil mesofauna in three types of land use in Bogor, West Java. Soil sampling has been carried out at 5 sample locations on forest, garden and dry land use types. Soil mesofauna extraction for each type of land use has used the method called tulgren, kempson extractor, and pitfall traps. The greatest abundance of soil mesofauna has been found in the type of upland land extracted using the litter kempson method with a density of 835 individuals $/ \mathrm{m}^{2}$. The highest diversity index of soil mesofauna has been found in the type of forest land use.

Keywords: barlesse tulgren, collembolan, kempson extractor, pitfall traps 


\section{PENDAHULUAN}

Intensifikasi penggunaan lahan dan beberapa aktivitas antropogenik meningkatkan perubahan-perubahan kualitas tanah. Kualitas tanah merupakan indikasi ekosistem biologi yang berkelanjutan di dalam tanah yang berkontribusi bagi pertumbuhan tanaman, hewan, dan manusia. Dekomposisi di dalam tanah akan berjalan cepat bila didukung oleh tingginya aktivitas fauna tanah. Keberadaan fauna tanah bergantung pada sumber energi seperti bahan organik dan biomassa hidup yang terkait dengan aliran siklus karbon di dalam tanah. Dengan ketersediaan energi dan nutrisi bagi fauna tanah, maka perkembangan dan aktivitas fauna tanah akan berlangsung baik dan memberikan pengaruh positif bagi kesuburan tanah. Kelompok mesofauna tanah memiliki panjang antara $100 \mu \mathrm{m}-2 \mathrm{~mm}$. Walaupun ukurannya sangat kecil, menurut Breure (2004) mikroorganisme di dalam tanah bertanggung jawab terhadap sebagian besar proses-proses biologis (60-80\%) yang berkaitan dengan siklus unsur hara dan dekomposisi bahan organik.

Mesofauna tanah sangat terkait erat dengan siklus unsur hara yang dilakukan oleh bakteri maupun fungi. Sumber makanan dari mesofauna tanah adalah seresah, sisa hewan dan tumbuhan yang mati, serta bakteri dan fungi. Secara tidak langsung mesofauna tanah berperan dalam agregasi tanah karena menghasilkan fecal pellet yang diproses didalam perutnya bersamaan dengan proses dekomposisi oleh bakteri maupun fungi. Hal yang sama, tumbuhan juga memberikan pengaruh terhadap komunitas organisme tanah baik mesofauna maupun bakteri melalui suplai karbon yang diberikan oleh eksudat akar. Sehingga aktivitas dan jumlahnya di rhizosfer akan jauh lebih besar dibandingkan dengan tanah disekitarnya (Zhangfeng et al, 2007). Keanekaragaman fauna tanah berkaitan dengan kemampuan individu dalam beradaptasi terhadap perubahan lingkungan dan ketersediaan makanan. Tutupan kanopi berkaitan pula dengan jumlah dan jenis serasah yang dihasilkan. Umumnya, ekosistem dengan vegetasi beragam memiliki tutupan kanopi, jumlah maupun ketebalan serasah yang tinggi. Tutupan kanopi dan jumlah serasah yang dihasilkan akan menciptakan kondisi iklim mikro yang sesuai dan ketersediaan makanan yang beragam bagi fauna tanah.

Karakteristik dari fauna tanah dapat digunakan sebagai indikator kualitas tanah. Sebagai contoh, kehadiran populasi atau individu spesifik yang memiliki pengaruh terhadap perubahan struktur tanah (Knoepp et al. 2000; Bartz et al., 2014). Sistem pengelolaan tanah dan karakteristik vegetasi berpengaruh terhadap kualitas tanah. Sistem tanpa olah tanah (TOT) atau pengolahan tanah minimum, tutupan lahan yang konstan, maupun sistem rotasi tanam memberikan kondisi yang dapat mempengaruhi perkembangan organisme di dalam tanah. Secara praktikal, pengolahan konvensional, monokultur, keberadaan tanaman-tanaman penutup tanah berpengaruh terhadap kemampuan organisme tanah untuk bertahan hidup (Bartz et al., 2013). Lebih lanjut, Wang et al. (2015) menjelaskan bahwa keragaman dari segi spasial dan temporal mempengaruhi kelimpahan dan struktur komunitas dari fauna tanah yang sangat mempengaruhi dekomposisi serasah. Selain itu, jenis mesofauna dan tipe serasah memberikan pengaruh terhadap proses dekomposisinya itu sendiri. Penelitian ini bertujuan untuk mengidentifikasi kelimpahan dan keragaman mesofauna tanah pada tiga tipe penggunaan lahan di Bogor, Jawa Barat. 


\section{METODE PENELITIAN}

\section{Lokasi Penelitian}

Penentuan lokasi penelitian menggunakan metode purposive sampling pada lahan yang dianggap representatif mewakili tiga penggunaan lahan yaitu lahan hutan, kebun dan tegalan. Sampel tipe penggunaan lahan hutan diambil di areal hutan CIFOR, Desa Situgede, Bogor Barat, Bogor $\left(6^{\circ} 33^{\prime} 07.5^{\prime \prime S} 106^{\circ} 45^{\prime} 10.5^{\prime \prime E}\right)$. Pengambilan sampel tanah pada tipe penggunaan lahan kebun dan tegalan dilakukan di Desa Babakan, Kecamatan Dramaga, Bogor (6³2'55.9"S $106^{\circ} 42^{\prime} 57.8^{\prime \prime E)}$. Pengambilan sampel dilakukan pada Mei 2016. Pada lahan tegalan, vegetasi didominasi oleh Coffea $L$ dan Hevea brasiliensis. Sedangkan pada lahan kebun, vegetasi didominasi oleh Zea mays.

\section{Metode Pengambilan Sampel}

Pengambilan sampel tanah dilakukan pada 5 titik lokasi sampel pada masing-masing tipe penggunaan lahan menggunakan tiga metode yaitu Berlese tullgren extractor, Kempson extractor dan Pitfall Traps. Ekstraksi menggunakan berlese tullgren dilakukan dengan membenamkan tabung polietilen $\varnothing 16 \mathrm{~cm}$ pada top soil. Selanjutnya tabung diangkat perlahan dan ditutup dengan kain poliester. Ekstraksi menggunakan Kempson dilakukan dengan mengambil sampel tanah top soil dengan ukuran $20 \times 20 \mathrm{~cm}$, selanjutnya dilakukan pengambilan sampel seresah. Sampel tanah dan sampel seresah dipisahkan dengan box persegi $20 \mathrm{~cm}$ dan ditutup rapat. Untuk metode Pitfall, gelas polietilen yang berisi surfaktan diletakkan ke dalam tanah, dan bagian atas ditutup dengan piringan stirofom dengan jarak $15 \mathrm{~cm}$.

\section{Ekstraksi mengggunakan Berlese Tullgren}

Sampel pada tabung poletilen diletakkan ke dalam lemari ekstraktor dengan posisi kain kasa di bagian atas, dan kain poliester di bagian bawah. Botol koleksi berisi yang berisi alkohol diletakkan di bagian bawah untuk menampung mesofauna tanah. Lampu ekstraktor dinyalakan selama 3 hari. Hasil ekstraksi disaring dan dipindahkan ke tabung yang bersi alkohol. Selanjutnya dilakukan identifikasi menggunakan mikroskop stereo.

\section{Ekstraksi mengggunakan Kempson}

Tanah yang telah diambil di lokasi pengambilan sampel dipindahkan ke wadah persegi. Selanjutnya diletakkan di atas wadah lain dengan ukuran yang sama dan telah berisi etilen glycol $50 \%$ untuk menampung mesofauna tanah yang keluar dari sampel tanah dan seresah. Setelah kedua wadah disatukan, kemudian diletatakkan pada Kempson extractor. Sampel tanah diesktraksi selama 7 hari sedangkan sampel seresah selama 5 hari. Selanjutnya, mesofauna ditambung ke dalam wadang penampung dan disaring untuk selanjutnya diidentifikasi menggunakan mikroskop.

\section{Identifikasi dan Analisis Data}

Identifikasi mesofauna tanah dilakukan menurut acuan Borror et al., (1992) dan Triplehorn \& Johnson, (2005). Densitas mesofauna dihitung berdasarkan persamaan Meyer (1996) : 


$$
\frac{I S}{A}=\mathrm{I} \cdot \mathrm{m}^{-2}
$$

Keterangan: $I S=$ rerata jumlah individu per sampel; $\mathrm{I}=$ populasi individu $/ \mathrm{m}^{2} ; \mathrm{A}=$ luas permukaan tempat penampung dalam $\mathrm{cm}^{2}$ (nilai dikonversi ke dalam $\mathrm{m}^{2}$ )

Keanekaragaman mesofauna tanah yang teramati di lapangan ditentukan berdasarkan Shannon diversity index (Magurran 2004) yang dapat dihitung melalui persamaan:

$$
H^{\prime}=-\sum_{t=0}^{s} p i \ln p i
$$

Keterangan:

$\mathrm{H}=$ Shannon diversity index $; \mathrm{pi}=\mathrm{ni} / \mathrm{N} ; \mathrm{ni}=$ Jumlah individu genus ke-I; $\mathrm{N}=$ Total jumlah individu

$\mathrm{s}=$ Total jumlah genus dalam contoh

Penilaian keragaman mesofauna tanah pada setiap tipe penggunaan lahan didasarkan atas nilai H' berdasaran Magurran (1987) dimana indeks keragaman dikategorikan dengan nilai sebagai berikut: <1,5 : keragaman rendah; 1,5-3,5: keragaman sedang, dan > 3,5: keragaman tinggi.

\section{HASIL DAN PEMBAHASAN}

\section{Kelimpahan Mesofauna Tanah}

Hasil pengamatan terhadap prosesntase kelimpahan mesofauna tanah pada masingmasing tipe penggunaan lahan disajikan pada gambar 1. Kelimpahan mesofauna tanah tertinggi menggunakan metode pifall traps terdapat pada tipe penggunaan lahan tegalan dengan total jumlah populasi sebesar 86 individu, tipe penggunaan lahan kebun sebesar 31 Individu, dan 19 individu pada tipe penggunaan lahan hutan. Prosentase tertinggi dari mesofauna tanah pada masing-masing penggunaan lahan tersebut adalah jenis Hyminoptera. Schultz and McGlyinn (2000), menyatakan bahwa Hyminoptera memiliki fungsi ekologis membantu tumbuhan dalam menyebarkan biji-bijian (dispersal), menggemburkan tanah, predator atau pemangsa serangga lain. Tingginya jumlah Hyminoptera mengindikasikan bahwa pada lahan-lahan tersebut masih tersedia sumber energi seperti sisa-sisa makanan, hewan dan tumbuhan yang mati. Kebanyaan spesies dari Hyminotera hidup pada koloni secara tetap dan tidak mudah untuk berpindah habitat (Agosti et al., 2000). Beberapa spesies dari Hymenoptera dapat beradaptasi untuk hidup pada lahan yang terdegradasi dan mengembangkan koloni dengan cepat. Jenis seperti ini dapat menjadi indikator adanya perusakan habitat atau terganggunya alam disekitarnya.

Kelimpahan mesofauna tanah tertinggi menggunakan metode barelesse turlgren terdapat pada tipe penggunaan lahan hutan sebesar 13 individu dan penggunaan lahan kebun sebesar 7 individu. Sedangkan pada lahan tegalan tidak ditemukan mesofauna. Pada tipe penggunaan lahan kebun, jumlah tertinggi terdapat pada jenis Collembola dan pada penggunaan lahan hutan jumlah tertinggi adalah jenis Hyminoptera. Tidak ditemukannya Collembola pada tipe penggunaan lahan tegalan diduga kuat karena adanya kontaminasi dari bahan-bahan agrokimia selama pengolahan lahan sebagaimana riwayat dari penggunaan lahan tegalan tersebut merupakan lahan dengan pertanian intensif. Hal ini sejalan dengan pernyataan Suhardjono (2000) bahwa mesofauna tanah Collembola dapat dijadikan sebagai indikator terhadap dampak 
penggunaan herbisida. Pada tanah yang tercemar oleh herbisida jumlah Collembola yang ada jauh lebih sedikit dibandingkan pada lahan yang tidak tercemar. Jumlah mesofauna yang terekstraksi menggunakan barlese tulgren lebih sedikit dibanding metode yang lainnya, hal ini karena penggunaan metode berlese tulgren tidak memiliki sistem pendingin sehingga saat ekstraksi terjadi over-heat sehingga banyak fauna yang mati, selain itu berkurangnya kadar air akibat radiasi panas membuat tanah menjadi lebih padat sehingga mesofauna yang terekstrak sedikit.

A

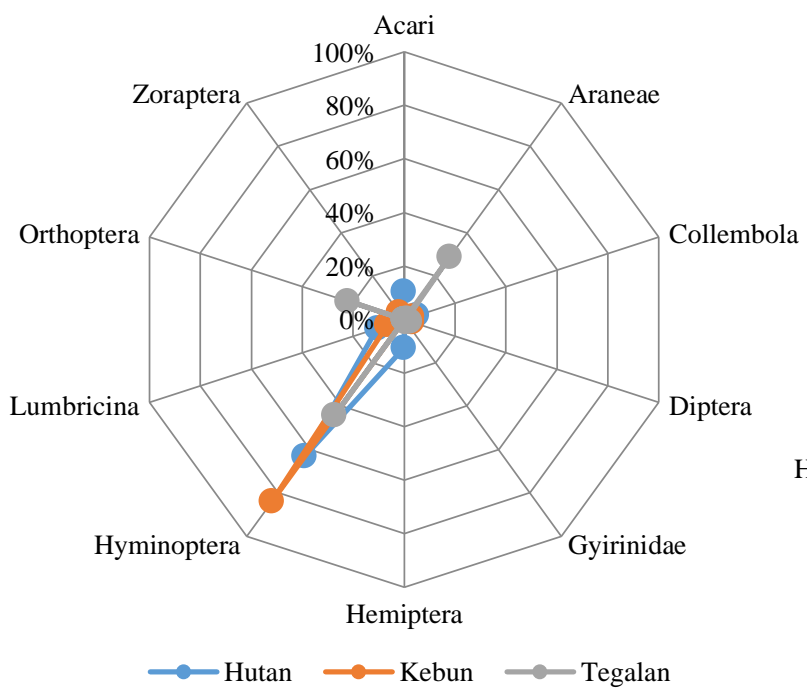

C

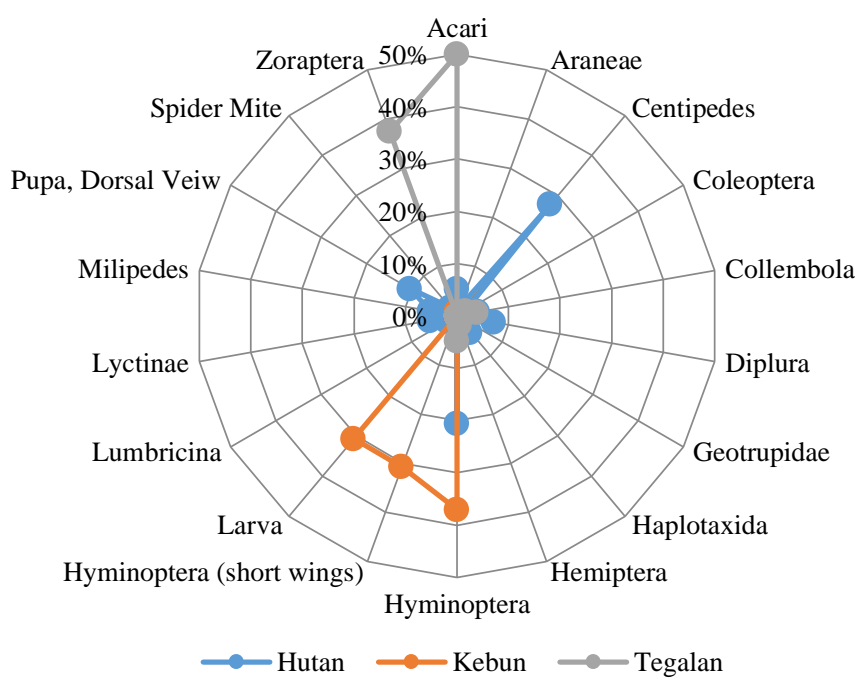

B

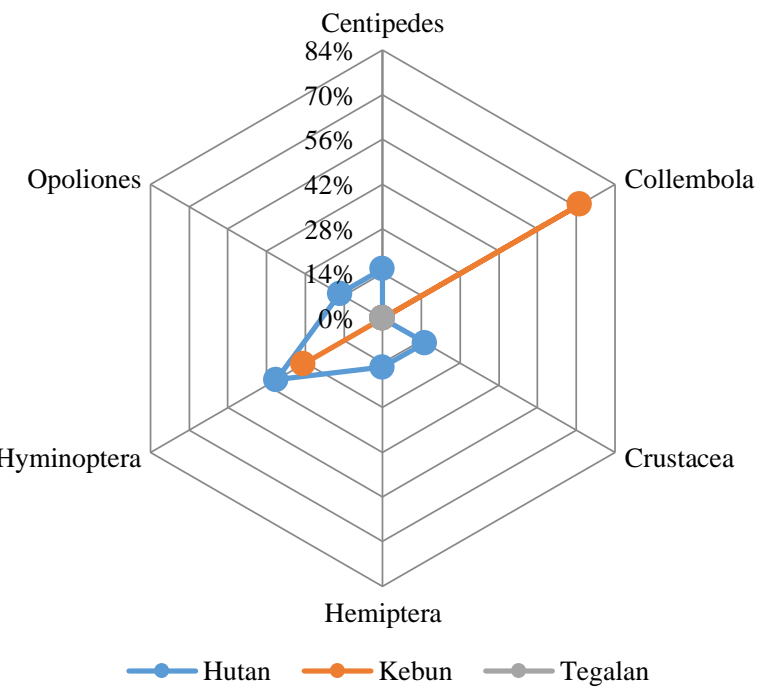

D

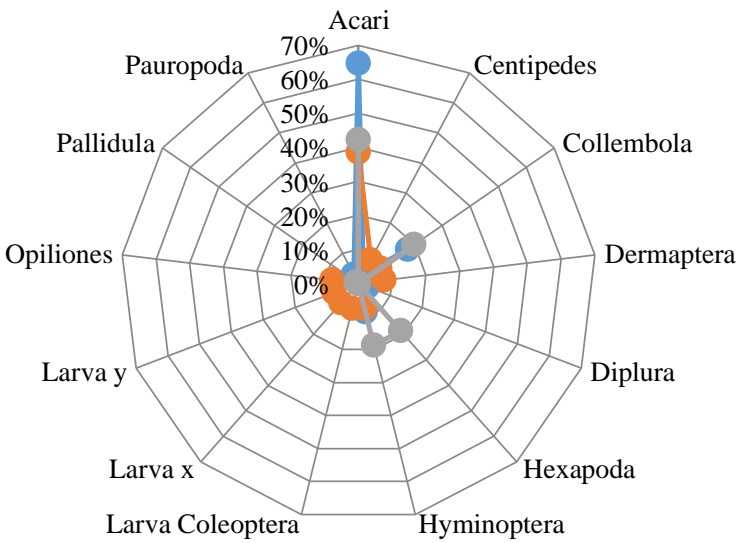

$\longrightarrow$ Hutan $\longrightarrow$ Kebun Tegalan

Gambar 1. Kelimpahan mesofauna tanah beberapa tipe penggunaan lahan dengan metode ekstraksi yang berbeda (A: pitfall traps; B: barlesse tulgren; C: kempson extractor; D: kempson extractor sampel seresah) 
Kelimpahan mesofauna tertinggi menggunakan metode Kempson terdapat pada tipe penggunaan lahan kebun sebesar 127 individu, lahan tegalan sebesar 104 individu, dan lahan hutan sebanyak 97 individu. Pada tipe penggunaan lahan kebun, sebanyak 37\% dari populasi didominasi oleh jenis Hyminoptera. Pada tipe penggunaan lahan tegalan, 50\% dari total populasi didominasi oleh Acari, dan $28 \%$ dari populasi lahan hutan didominasi oleh Centipedes.

Pada sampel seresah, populasi tertinggi terdapat pada tipe lahan tegalan sebanyak 6680 individu, hutan 1327 individu, dan kebun 507 individu. Dari total populasi masing-masing tipe penggunaan lahan, 42\% lahan tegalan, 38\% dari lahan kebun, dan $65 \%$ dari lahan hutan didominasi oleh Acari. Karakteristik lahan tegalan yang digunakan sebagai lokasi sampling memiliki karakter tanpa naungan dengan riwayat tanam sebelumnya adalah ketala pohon. Berdasarkan Borror et al. (1996) Acari banyak terdapat di dalam tanah dan reruntuhan organik dan biasanya jumlahnya melebihi Arthropoda lainnya. Lavelle dan Spanyol (2001) menyatakan bahwa Acari memiliki ketahanan yang tinggi terhadap stress air dan suhu, mereka dapat bertahan dalam kodisi kering sebelum berpindah ke area basah.

\section{Densitas dan Keragaman Mesofauna Tanah}

Densitas dan indeks keragaman mesofauna tanah pada beberapa tipe penggunaan lahan disajikan pada tabel 1. Penggunaan metode pitfall trap hanya digunakan untuk mengobservasi fauna tanah dipermukaan. Sehingga, perhitungan densitas individu $/ \mathrm{m}^{2}$ dan keanekaragaman (indeks Shannon) tidak dapat dilakukan karena luas sampling yang tidak sama. Densitas tertinggi terdapat pada penggunaan lahan tegalan menggunakan metode kempson sampel seresah. Jumlah individu tanah pada tegal lebih banyak apabila dibandingkan dengan penggunaan lahan pada kebun dan hutan. Akan tetapi keanekaragaman fauna pada kebun adalah yang paling banyak dibandingkan tegal. Hal tersebut karena kebun memiliki sumber makanan yang lebih banyak sehingga keanekaragaman lebih tinggi didapat pada tanah kebun.

Tabel 1. Densitas dan indeks keragaman mesofauna tanah beberapa tipe penggunaan lahan

\begin{tabular}{cccc}
\hline Jenis Metode & Penggunaan Lahan & Densitas (individu/m ${ }^{2}$ ) & $\begin{array}{c}\text { Indeks Diversitas } \\
\text { (Shanon) }\end{array}$ \\
\hline \multirow{2}{*}{ Kempson } & Hutan & 93 & $\mathbf{0 , 8 9}$ \\
& Kebun & 128 & 0,42 \\
& Tegalan & 170 & 0,47 \\
\hline \multirow{2}{*}{ Kempson* } & Hutan & 166 & 0,50 \\
& Kebun & 55 & 0,69 \\
& Tegalan & $\mathbf{8 3 5}$ & 0,57 \\
\hline \multirow{3}{*}{ Berlese tulgren } & Hutan & 2 & 0,52 \\
& Kebun & 2 & 0,21 \\
& Tegalan & 0 & 0 \\
\hline
\end{tabular}

Keterangan: *Mesofauna tanah diesktrasi dari seresah pada titik dan ukuran luas sampel yang sama

Populasi, biomassa dan diversitas fauna tanah dipengaruhi oleh praktek pengelolaan lahan dan penggunaannya. Pada tipe lahan yang kualitasnya tergolong masih rendah menyebabkan hanya fauna tanah jenis tertentu yang mampu bertahan hidup, sehingga diversitas 
tanah baik yang aktif di permukaan tanah maupun di dalam tanah juga sangat rendah. Tinggi rendahnya jumlah fauna tanah ditentukan oleh banyak faktor diantaranya sumber makanan yang cukup dan kondisi lingkungan yang sesuai.

Dari ketiga tipe penggunaan lahan tersebut, lahan hutan memiliki indeks diversitas yang paling tinggi, kemudian diikuti oleh kebun dan terakhir oleh tipe lahan tegalan. Lahan hutan memiliki indeks diversitas tertinggi karena tingginya keanekaragaman tumbuhan di dalamnya sehingga variasi dan jumlah seresah yang dihasilkan lebih besar. Hal ini mempengaruhi komposisi makanan yang dibutuhkan bagi mesofauna tanah. Semakin besar variasi serasah, maka semakin tinggi pula keanekaragaman fauna tanah (Solihin 2000). Menurut Rahmawaty (2004), komposisi tegakan yang terdiri dari beberapa spesies pohon menghasilkan serasah dengan humifikasi yang cepat dan menumbuhkan berbagai tumbuhan bawah. Banyaknya tumbuhan bawah ini menjadi sumber makanan bagi fauna tanah. Tingginya indeks diversitas dipengaruhi oleh faktor lingkungan berupa kandungan bahan organik, dan kelembaban tanah. Hutan memiliki kelembaban yang relatif tinggi, keadaan seperti ini menguntungkan bagi fauna tanah untuk bertahan hidup menghadapi musim kemarau. Faktor-faktor yang mempengaruhi keberadaan fauna tanah di hutan, adalah: 1) struktur tanah berpengaruh pada gerakan dan penetrasi; 2) kelembaban tanah dan kandungan hara berpengaruh terhadap perkembangan dalam daur hidup; 3) suhu tanah mempengaruhi peletakan telur; 4) cahaya dan tata udara mempengaruhi kegiatannya.

Hal tersebut dapat dikatakan bahwa bahan organik atau sumber makanan sangat mempengaruhi keanekaragaman fauna tanah. Tipe penggunaan lahan saat sampling merupakan hutan alami tanpa adanya pengolahan sehingga keragamannya tinggi. Hal ini juga sejalan dengan Harahap et al., (2016) yang menyatakan bahwa indeks keragaman fauna tanah dengan perlakuan tanpa olah tanah memiliki indeks keragaman yang lebih tinggi dibandingkan dengan perlakuan sistem olah tanah intensif. Selain itu, Waktu merupakan salah satu faktor yang mempengaruhi indeks keragaman $\left(\mathrm{H}^{\prime}\right)$. Faktor waktu berkaitan erat dengan dengan tipe vegetasi yang berkembang diatasnya. dengan demikian, semakin lama lahan tersebut tidak diolah dan vegetasi yang tumbuh sudah menyerupai hutan, maka jumlah spesies dan kelimpahan fauna tanah akan meningkat (Hilwan \& Handayani 2013). Kelimpahan fauna tanah pada tegakan yang rapat lebih tinggi daripada tegakan jarang. Hal ini menunjukkan dengan tutupan tajuk yang lebih rapat, maka sinar matahari yang masuk ke dalam tegakan sedikit dan menjadikan tanah lebih lembab sehingga proses dekomposisi serasah lebih lambat dan kelimpahan makrofauna tanah juga akan meningkat (Wibowo \& Rizqiyah, 2014). Hutan merupakan habitat alami bagi fauna tanah untuk mempertahankan kesinambungan hidupnya. Fauna tanah sangat berperan penting dalam menjaga keseimbangan ekosistem hutan. Kelangsungan hidup fauna tanah bergantung pada kelestarian ekosistemnya (Haneda dan Asti 2014). Akan tetapi, berdasarkan shannon diversity index nilai $\mathrm{H}^{\prime}$ tersebut dalam kategori keragaman mesofauna tanah yang rendah. 


\section{KESIMPULAN}

Kelimpahan mesofauna tanah terbesar terdapat pada tipe penggunaan lahan tegalan yang diekstraksi menggunakan metode kempson sampel seresah dengan densitas 835 individu/ $\mathrm{m}^{2}$. Indeks diversitas tertinggi terdapat pada tipe penggunaan lahan hutan yang diekstraksi menggunakan metode kempson (0.89). Keragaman mesofauna pada tipe penggunaan lahan hutan, kebun, dan tegalan tergolong rendah.

\section{DAFTAR PUSTAKA}

Agosti. D. Majer, D., Alonso L.E., Schultz, Tr. 2000. Ants Standard Methods For Measuring And Monitoring Biodiversity. Washington: Smithsonian Institution Press.

Bartz, M. L. C., Brown, G. G., Orso R., Mafra A L. 2014. The Influence Of Land Use Systems On Soil And Surface Litter Fauna In The Western Region Of Santa Catarina. Revista Ciência Agronômica, 45(5) (Especial), P. 880-887.

Bartz, M. L. C.; Pasini, A.; Brown, G. G. 2013. Earthworms As Soil Quality Indicators In Brazilian No-Tillage Systems. Applied Soil Ecology. V. 69, 39-48.

Breure, A.M. 2004. Soil Biodiversity: Measurements, Indicators, Threats and Soil Functions. International Congference Biology September $15^{\text {th }}-17 \mathrm{t}^{\mathrm{h}}$ Spain.

Haneda, F.,N. Asti, W. 2014. Keanekaragaman Fauna Tanah Dan Perannya Terhadap Laju Dekomposisi Serasah Karet (Hevea Brasiliensis) Di Kebun Percobaan Cibodas-Ciampea Bogor. Bogor: Institut Pertanian Bogor. Jurnal Silvikultur Tropika 05(1), Hal 54-60.

Harahap A.I.P, Utomo M, Yusnaini S, Arif S. 2016. Pengaruh Sistem Olah Tanah Dan Pemupukan Nitrogen Terhadap Keanekaragaman dan Populasi Mesofauna Pada Serasah Tanaman Padi Gogo (Oryza sativa L.) Musim Tanam Ke-46. J. Agrotek Tropika. 1: 86 92.

Hilwan, I. dan E. P. Handayani. 2013. Keanekaragaman Mesofauna dan Makrofauna Tanah pada Areal Bekas Tambang Timah di Kabupaten Belitung, Provinsi Kepulauan BangkaBelitung. Jurnal Silvikultur Tropika 04(1) $35-41$ p.

Knoepp, J. D. Et Al. 2000. Biological Indices Of Soil Quality: An Ecosystem Case Study Of Their Use. Forest Ecology And Management. V.138, P. 357-368.

Lavelle P And Spain Av. 2001. Soil Ecology. Kluwer Acad. Pub. Dordrecht.

Magurran E Anne. 2004. Measuring Biological Diverisity. Blackwell Science Ltd.

Rahmawaty. 2004. Studi Keanekaragaman Mesofauna Tanah Di Kawasan Hutan Wisata Alam Sibolangit (Desa Sibolangit, Kecamatan Sibolangit, Kabupaten Daerah Tingkat Ii Deli Serdang, Propinsi Sumatera Utara). Medan : Universitas Sumatera Utara.

Schultz, T. R. And Mcglynn, T. P. 2000. The Interaction Of Ants With Other Organisms./ In: Agosti, D., Majer, J., Alonso, E. Et Al. (Eds), Ants: Standard Methods For Measuring And Monitoring Biodiversity. Smithsonian Institution Press, Pp. 35/ 44.

Solihin. 2000. Keanekaragaman Binatang Tanah Pada Berbagai Tegakan Hutan. Bogor :IPB Press. 
Suhardjono Yr. 2004. Buku Pegangan Belajar Collembola (Ekor Pegas). Bogor (Id) : Museum Zoologicum Bogoriense.

Triplehorn Ca And Johnson Nf. 2005. Borror And Delong's Introduction To Study Of Insect Eds7. Thompson Learning.

Wang Z, Yin X, Li X. 2015. Soil Mesofauna Effects On Litter Decomposition In The Coniferous Forest Of The Changbai Mountains, China. J. Applied Soil Ecology 92:64-71.

Wibowo, C. and W. Rizqiyah. 2014. Diversity of Soil Macrofauna on Various Stand Types in Gunung Walat University Forest, Sukabumi, West Java. Journal of Silvikultural Tropic 05(1) pp. 43-48.

Zhanfeng L., L. Guohua, F. Bojie And Z. Xiaoxuan. 2007. Relationship Between Plant Species Diversity And Soil Microbial Functional Diversity Along A Longitudinal Gradient In Temperate Grasslands Ofhulunbeir, Inner Mongolia, China. Ecol Res (10): 1172-1179. 